\title{
Canadians still waiting for timely access to care
}

\author{
Cite as: CMAJ 2017 March 6;189:E375-6. doi: 10.1503/cmaj.1095400
}

anadians wait longer for medical care than their international peers, according to survey results reported by the Canadian Institute for Health Information (CIHI). The Commonwealth Fund survey polled adults about wait times and patient-centred care in 11 developed nations, including Canada, the United States, the United Kingdom, Australia, New Zealand and some European countries.

Canada performed "below average and bottom of the pack" on most measures of timely access to care, says Christina Lawand, senior researcher of health system analysis and emerging issues at CIHI. However, once patients access care, "they tend to be very satisfied," she says.

Nearly three-quarter of Canadians rated their primary care as excellent or very good, but $55 \%$ said the health system needs fundamental changes to work better. "It's a bit of a mixed picture," Lawand says.

In top performing countries, like France and the Netherlands, most patients can email their family doctor to ask questions or book same-day appointments. It's rare to wait in emergency departments for more than four hours or to worry about the cost of medications. That level of access is a far cry from the experiences described by Canadian respondents.

Although $93 \%$ of Canadians have a regular doctor or place of care, only $43 \%$ were able to get same-day or next-day appointments, compared to $77 \%$ in the Netherlands or an average $57 \%$ across the 11 peer countries. Canadians reported the longest emergency department waits, with $29 \%$ waiting four or more hours compared to just $1 \%$ in France and $11 \%$ on average. Canada also had the slowest access to specialists; more than half of Canadians waited longer than four weeks for an appointment, compared to less than a quarter of Swiss respondents and a third of patients across the comparator nations.

\section{Why no progress?}

The survey results suggest Canada's bottleneck starts in primary care, explains Lawand. Canadians were the heaviest users of emergency departments, but $41 \%$ said their last visit was for a condition that could have been treated in primary care, if their regular providers had been available. Only a third of Canadians could access care on evenings, weekends or holidays without going to the emergency department.

There also seems to be a shortfall in the physician workforce. Canadians depend heavily on their doctors, reporting 7.6 visits per person in 2016 compared to the international average of 5.8 visits. Less than a quarter of Canadians have nurses or other health professionals besides their doctors routinely involved in their care. Despite this heavy use of physician services, Canada has only 2.5 physicians per 1000 people, one less per 1000 people than the international average.

Canada's physician workforce has grown steadily over the past decade, "but we're still seeing patients reporting the same waits they were 10 years ago," says Lawand. Demand may be outpacing supply, or Canada may need to change how it uses doctors, she says. "Some of the countries that focused on a multidisciNetherlands, seem to have better results in timely access."

The survey also sheds light on financial insecurity that Lewand says may be driving high demand for health services. plinary approach to primary care, like the

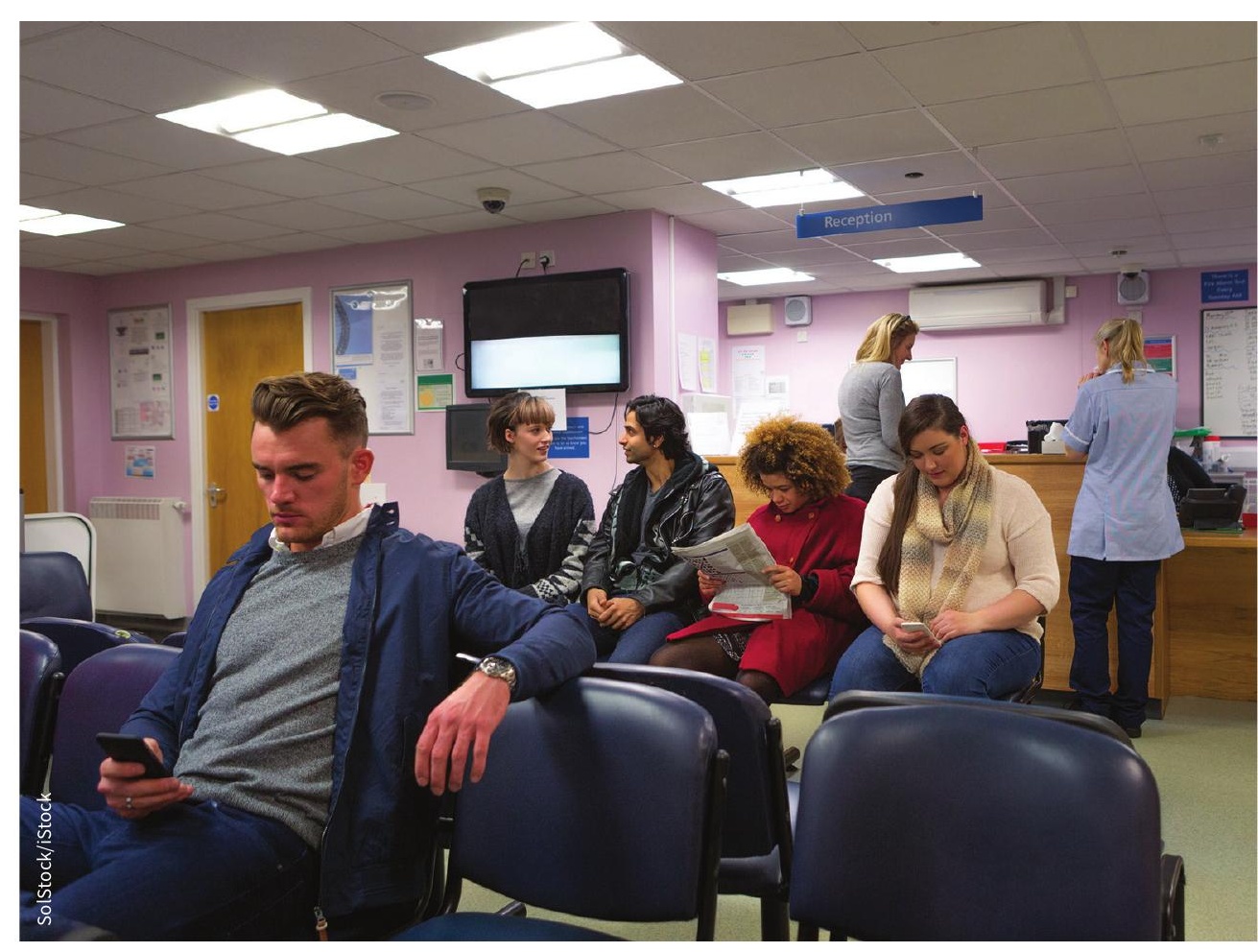

Canada has the longest waits for family doctors, specialists and emergency care of 11 peer

countries. 
"What food you eat, what environment you're living in, whether you have income security, those questions will have a profound impact on your health," she explains.

Ten percent of Canadians didn't fill a prescription or skipped doses because of the cost, compared to $2 \%$ of British people, and $28 \%$ of Canadians skipped dental care versus $11 \%$ of people in the Netherlands. Although Canadians received more counselling about nutrition than people in other countries, nearly one in five young adults reported often or always worrying about having enough money for healthy food. Lewand says it was especially troubling to see that one in 10 of Canadians were usually or always worried about having enough money to keep a roof over their heads.
"We weren't expecting to find anxiety levels so high."

Access problems are further complicated by poor communication, Lawand says. Nearly one in five Canadians reported receiving conflicting information from health providers, versus one in 10 in the Netherlands. One in 20 Canadians have online access to their health information, and fewer still are able to ask their doctors questions by email, compared to about one in four people in France.

\section{Satisfaction still high}

However, there were improvements in terms of satisfaction. Only $6 \%$ of Canadians said their doctors ordered redundant medical tests, down from $8 \%$ in 2010 . And once patients and physicians are face to face, "things seem to go really well," Lawand says.

Canada performed at or above average on most indicators of patient-centred care. Notably, more than half of Canadians said their primary care providers always know important information about their medical history, spend enough time with them, involve them in decisions, and explain things in a way that's easy to understand. Respondents also reported high satisfaction with hospital care; $78 \%$ said doctors always treated them with respect.

Lawand says this suggests that wait times, although important, "are one piece, but not the entire puzzle when it comes to the health system."

Lauren Vogel, CMAJ 